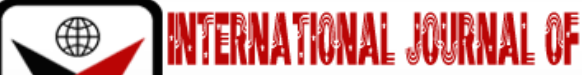

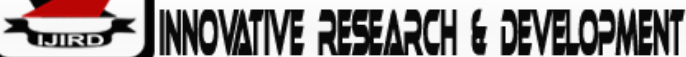

ISSN 2278-0211 (Online)

\section{The Multilingual Situation of Ghana and How Multilingualism Contributes to National Development}

\author{
Clever Susuawu \\ Tutor, Department of Languages, Peki College of Education, Ghana \\ John Asiegbor \\ Tutor, Department of Languages, Peki College of Education, Ghana
}

\begin{abstract}
:
The main concern of this paper is to address how multilingualism has become very common around the world. It is asserted that about half of the world's population speaks more than one language. The greatest challenge facing policy makers today is how to maintain national cohesion through language policy for schools in the country. The challenge in language education is not only to ensure a meaningful mother-tongue education, but also to evolve a viable programme in which both mother tongue and other tongue teaching reinforce each other. It is revealed that the additive multilingualism method is encouraged to avoid language shift which will eventually lead to its death. There is the problem of communication. The nation cannot function unless there are one or more languages that can be used for national communication and administration. It is realized that if a choice has to be made, it will be very difficult to determine the relevant criteria to be used in making the choice. It is also realized that in terms of education, the particular language to be used as the media of instruction and which should be taught only as subjects will be a major problem. Finally, it is concluded that, if a choice has to be made, the basis for recognition of the 'approved languages' will also be problematic.
\end{abstract}

Keywords:Multilingualism,languages, communication,mother- tongue,development

\section{Introduction}

Language shift, a process which may lead speakers to use their language in fewer domains with respect to other languages or even lose proficiency in their language altogether in favour of other languages, is a prominent concept in linguistics. Kachru (1986) holds the view that 'English in Ghana is considered as a symbol of modernization, a key to expand functional and an extra hand for success and mobility in culture and linguistically complex and pluralistic societies. Multilingual language shift processes, which involve situations in which different types of language shift take place concurrently or sequentially in a country, are thus very different from simple language shift situations in less multilingual set-ups. The purpose of this academic exercise is to discuss the multilingual situation of Ghana and explain how multilingualism affects or contributes to national development.

While talking about multilingual developing nation in Africa, Ghana comes first. This study aims to find some of the answers like most suitable language, medium for training citizens etc.

\section{Statement of the Problem}

It has been established in the related literature that various scholars have over the years conducted research on multilingualism and looked at various components and applied varied theoretical frameworks, however: there are a lot of gaps which need to be filled. It is upon this discovery that this current study aims at analysing the multilingual situation of Ghana and how multilingualism contributes to national development.

\section{Purpose of this Study}

The main purpose of this study is to explore the multilingual situation of Ghana and identify how multilingualism contributes to national development. 


\section{Research Questions}

- How is the multilingual situation of Ghana?

- How does multilingualism contribute to national development?

\section{Literature Review}

According to Aronin, L. (2019), multilingualism is a complex, effervescent and everintriguingooccurrence. Here, multilingualism refers to the use of three and more languages. Most of the countries now prefer multilingualism like Japan and Iceland etc. It has become a part of progress and maintenance of modern civilization(Aronin\& Singleton, 2012). It helps to build "multicompetence in its own right"Cook (2005a, p. 3).Bilingual refers to high levels of proficiency in two languages in the written and the oral modes. But if any fluency related problem happens, it also can be considered as bilingual to some extent. Such persons may also called to be 'more bilingual' than monolinguals. "Language" is understood here as a variety that a group adopts as a habitual way for communication.

It is very paramountand logical to differentiate individual multilingualism from societal multilingualism(Andrews, 2014: 49; Donald, 2004) and it is impossible to study individual multilingualism without considering its societal dimensions.

According to Edwards (2007),societal multilingualism refers to the backgrounds, settings, directive, methodand practices of use of languages in different kinds of communities, organizations and groups. There are communities and territories where multiple languages coexist side by side. Switzerland is a good example of this. According to Barnard (2016), the existence of language was before the modern humans populated. Aronin\&Jessner (2015) highlighted the importance of multilingualism. As per De Angelis (2005), it needs a separate principle for handling.

\section{Discussion}

If the notion exists that a personis a social being, then it is obvious that contact with other people and, in particular, language contact is likely to happen. Multilingualism as a positive phenomenon has entered the public eye more and more over the last few decades and has received targeted promotion. To give an example, the European Union has set itself the goal of promoting two languages in addition to the first language using various measures. In research, the term multilingualism is nowadays of the utmost importance in forming a comprehensive bracketing of interests, which over the past few decades have been driven forward with various methodologies (Li Wei \& Moyer, 2008). Multilingualism is not a completely new research topic. The term sometimes stands for an extended view of the earlier research into bilingualism and second language acquisition (SLA; De Angelis, 2007).It is very obvious to claim that multilingualism has become a common language phenomenon among almost every country in the world including Ghana. The literature stated that about half of the world's population speaks more than one language. This gives an indication that no country is monolingual but rather multilingual. Ghana, like most African countries, is a multilingual nation. Various studies have revealed that Ghana has between 45 and 60 indigenous languages. Out of these indigenous languages, ten local languages have officially emerged and been recognized by the government and used in the various schools in the country.

As far back as the 1930s, Twi, Fante, Ga, and Ewe were General Certificate Ordinary Level (GCE ' $O$ ' Level) examination subjects and were counted towards exemption from the matriculation examination of the University of London (Andoh-Kumi 1994). This considerable linguistic and ethnic diversity potentially creates problems for effective national communication and integration. Faced with a multilingual situation like this, the government of Ghana has to lay down policy guidelines that should bring about not only effective intranational communication but also a feasible international communication.

Apart from language contact, an important influence on syntactic change is also exerted by different readings associated with different word order patterns in terms of information structure. It is noted that information structure has not only turned out to account for the coexistence of syntactic variants within one language, whatever synchronic snapshot on the diachronic axis one considers, but it has also qualified as an active participant in influencing and even causing syntactic change, hence 
dispensing with the need to invoke parametric change or variation in each and every of the relevant cases (Kupisch\&Rinke 2007).

Mother Tongue is an instrument for transmitting culture and for the socio-economic development of the individual. The celebration of the day provides an opportunity to recognize linguistic diversity and the importance of multilingual education. In a globalized world, knowledge of other languages is essential for enterprises that want to operate internationally. As a lingua franca in a large part of the world, English is an obvious choice as a common language of communication. However, being able to communicate in more languages gives a firm competitive advantage over its rivals. Not only do certain countries use a lingua franca other than English (e.g., French, Spanish, Russian and Chinese). An enterprise can also increase its success on foreign markets by using its customers' native languages. Doing so expresses respect towards the customers' culture and identity, fosters trust and goodwill, proves the enterprise's long-term commitment, helps it gain a better insight into local legislation and customs, and enables it to make its market research and advertising campaigns more effective. Moreover, operating in several languages makes it possible to recruit from a larger pool of candidates and to make its workforce potentially more dynamic by making it more diverse.

It is noticed in the literature that in the linguistically diverse context; however, they also accrue to enterprises that operate locally: a multilingual staff enables them to create a stronger bond with their customers and other stakeholders. Until not so long ago, many in Europe believed that trying to master more than one language, especially languages less "distinguished" than Latin, Greek, French or German, would confuse the mind, make people asocial and even lead to criminal behaviour and mental illness. As a result of considerable research in the last few decennia, this view is no longer held by anyone in the scientific community.

Kupisch\&Rinke (2007) have argued that this diachronic variation does not mirror a parametric change, but rather needs to be considered as the reflex of a general expansion of the article into possessive contexts and its subsequent grammaticalization towards the spell-out of the definiteness feature. Culturally, being multilingual facilitates the discovery of different cultures, their literatures and traditions. Socially, it opens up the possibility of richer contacts both when travelling abroad and with fellow members of one's own multilingual community and thereby tends to foster mutual understanding, tolerance and trust. In the case of families with foreign or mixed origins, it has the further advantage of enabling children to maintain an intimate bond with their extended families and a strong connection with their cultural roots, without this preventing them from integrating into the local community. In addition to this communicative advantage, a growing number of recent studies have documented a range of cognitive and even neurological advantages of early multilingualism if properly managed. According to these studies, multilingual children tend to score better in terms of mental flexibility, creativity and analysis, and they tend to keep these advantages later in life.

As a result of the multilingual status of Ghana, English language has become a compulsory subject in the area of Ghanaian education from the basic schools to the secondary schools. Pupils must pass the English Language examination before they would be able to enter any tertiary institution. English Language is the first language accepted and use in the country as a Ghanaian international language. English Language is an official language in the sense that it is the language in the process of bureaucratic communications, it is the language used in business, offices, law, parliament, trade and commerce, interviews, aviation, radio stations, and in all other transactions. English Language is the lingua franca in Ghana. English Language has become the requirement in a number of fields, occupations, professions such as medicine and computing. English Language is the medium of instruction from primary four to the university level.All public examinations are set in the English language. Due to the multilingual nature of Ghana another English-Ghanaian English emerged. It constitutes the deviant means of communication that both educated and uneducated people use to express themselves at places of work and other places and social gatherings. It is a type of British Standard English but has a lot of injections of vocabulary items from Ghanaian origin or English words. For example, I like eating fufu, I love drinking kasapreko. Considering the types of English spoken in Ghana, they are pidgin, Broken and Standard English. Ghanaianism implies that there are certain English expressions that are formed and used by Ghanaians in their everyday expressions 
which are unknown in the Standard English Language.Multilingualism is now widely regarded as an asset, for two main reasons. The most obvious advantage of multilingualism for individuals is that it amplifies their communication potential. This is relevant in many contexts. Professionally, competence in more than one language often increases the probability of finding a job or of accessing better jobs.

In the 20th century, many held the view that multilingualism was bad not only for individuals, but also for communities. In the ideal nation-state, so they believed, the citizens should share one language and eradicate all others, for linguistic diversity and the multilingualism it generates could corrupt the soul of the nation, undermine the dynamism of its cultural life, threaten civic peace and national unity, and hamper economic development. Today, the conjunction of globalization and migration has forced us to accept linguistic diversity as a central and irreversible fact of 21st century communities. In the worst case, linguistic diversity can generate a fragmentation of the community into sub-communities that are unable to communicate with each other or to share a common project. More generally, one must acknowledge running the economic, social and political life of a linguistically diverse community is often more difficult, more laborious, and more conflict-ridden than that of a monolingual one.

The language of education in multilingual societies has always been a matter of concern to educators and educational planners. As Ouadraogo (2000, p. 89) has pointed out "Education and Language issues are very complex in Africa because of the multi-ethnic, multi-lingual situation". The situation is even more severe when the official language of the nation is different from any of the indigenous languages. There is always controversy over which language to use in school especially at the lower primary level in multilingual societies. Before the advent of formal education, our forefathers used the mother tongue which is the indigenous language in so many ways to train their children. This linguistic training was seen in the use of proverbs, folktale sessions in the homes during the evenings, child play, moon- light games, but to mention just a few. Of major signify- canes were the traditional values and morals that were derived from the linguistic genres. Unfortunately, with the advent of formal education, much attention had been focused on the lingua franca of the country; the English language. This has been done at the detriment of the mother tongue. As a result, the Ghanaian languages have been relegated to the back- where the languages are used, they are adulterated with a lot of code mixing or switching in the process. The individual needs to learn a lot of language to be able to function effectively in the Ghanaian society. Because Ghana has no national language, for this reason, code mixing or switching and choosing a lingua franca were the only means to communicate. The multiplicity of indigenous language poses problems.

The choice of lingua franca for international communication is one of the problems. The choice of lingua franca for formal communication has also become controversial. There would be British Standard English with a near Received Pronunciation accent based on the fact that Ghana is a multilingual nation. There would be British Standard English with a local accent. There would be local educated English variety. There would be West African pidgin Apart from the environment. Some factors accounted for the variation in pronunciation in the speech sounds of a non-native speaker. Some English speech sounds cannot be found in some of the Ghanaian languages and speakers of these languages tend to substitute sounds for those they lack. Multilingualism indeed is the widespread learning of several languages by the members of a community is the glue, the network of bonds that can turn linguistic diversity from a handicap into an asset. In particular, providing there is sufficient competence in shared local languages, the lasting presence of people with a large number of different native tongues in a place like Brussels offers not only a wonderful opportunity for the local exploration and appreciation of a great variety of cultures, but also a wealth of economically valuable connections with countless places in the world. Hence the importance of promoting multilingualism through the learning of linking languages in the Brussels case, French, Dutch and English while at the same time cherishing and maintaining as many as possible of the other languages in the community. This multiplicity of native languages or of languages known by the members of a community whether a family, an organization, a firm, a school, a neighbourhood, a town, a region or a country can be called linguistic diversity. 
Communities that are officially multilingual or in reality, linguistically diverse may vary greatly in the extent to which their members are multilingual. People can be called multilingual (or plurilingual) if they know two or more languages, whatever the level of competence. Some may know two or more languages so well that they may pass as monolingual native speakers of each of their respective languages in all situations and under all circumstances. Such cases are extremely rare. Most multilingual people master their various languages to different degrees. Moreover, what can be considered their stronger or weaker language may change from one context to another and in the course of their lives. Some multilingual people may be better in one language (for example, the English, French, Ewe and Twui they learned at school) for writing formal texts but better in another, even one they cannot. Thus, multilingualism comes in many shades. Ultimately, whether you are multilingual and how multilingual you are depends on how you perceive yourself and on whether you have the will to put into practice the competence you possess. The various language groups that make up the community are unable to communicate with one another. At the other extreme, they are all fluent in each other's languages. A truly multilingual community is one whose members are themselves multilingual. Akan will be truly multilingual when all its residents will be multilingual to a varying but significant degree.

\section{Conclusion}

To this end, Multilingualism has become very common around the world. In the literature, it is argued that about half of the world's population speaks more than one language. The greatest challenge facing policy makers is how to maintain national cohesion through language policy for schools in the country. The challenge in language education is not only to ensure a meaningful mother tongue education, but also to evolve a viable programme in which both mother tongue and other tongue teaching reinforce each other. The additive multilingualism method is encouraged to avoid language shift which will eventually lead to its death. There is the problem of communication. The nation cannot function unless there are one or more languages that can be used for national communication and administration. If a choice has to be made, what should be the relevant criteria to be used in making the choice? There is the problem of education. Which of the many languages are to be used as media of instruction and which should be taught only as subjects? Again, if a choice has to be made, what should be the basis for recognition of the 'approved languages'?

\section{References}

i. Andoh-Kumi, K. (1994). Topics in Ghanaian language education (Unpublished)

ii. Andrews, E. (2014).Neuroscience and Multilingualism.Cambridge: Cambridge University Press.

iii. Aronin, L. (2006). Dominant language constellations: An approach to multilingualismstudies. In M. Ó Laoire (ed.) Multilingualism in Educational SeAronin, L. and D.

iv. Aronin, L. (2019). What is Multilingualism?In David Singleton and Larissa Aronin (eds.), Twelve Lectures in Multilingualism. (pp. 334). Bristol: Multilingual Matters. http://www.multilingual-matters.com/display.asp?isb=9781788922050.

v. Aronin, L. and Jessner, U. (2015). Understanding current multilingualism: What can the butterfly tell us? In C. Kramsch and U. Jessner (eds) The Multilingual Challenge (pp. 271291).Berlin: De Gruyter.

vi. Aronin, L. and Singleton, D. (2012).Multilingualism. Amsterdam: John Benjamins.

vii. Barnard, A. (2016).Language in Prehistory. Cambridge: Cambridge University Press.

viii. Cook, V. J. (2005a). Multi-competence: Black Hole or Wormhole? (Draft of write-up of SLRF paper,2005). Retrieved September 6, 2011, from http://homepage.ntlworld.com/vivian.c/Writings/Papers/SLRF.htm

ix. De Angelis, G. (2007). Third or additional language acquisition. Clevedon, England: Multilingual Matters.

x. Donald, M. (2004).The definition of human nature. In D. Rees and S. Rose (eds) The New Brain Sciences: Perils and Prospects (pp. 34-58). Cambridge: Cambridge University Press.

xi. Edwards, J. (1994). Multilingualism. London: Penguin Books. 
xii. Hakuta, K. (1990). Bilingualism and bilingual education: A research perspective.

xiii. Kachru B. B. (1986). The alchemy of English. The spread, functions and models of non-native Englishes. Oxford: Pergamon Press.

xiv. Kupisch, T. \& E. Rinke (2007). Italienische und portugiesische Possessiv pronominaim diachronischenVergleich: DeterminantenoderAdjektive?Universität Hamburg: ArbeitenzurMehrsprachigkeit $\mathrm{N}^{\circ} 78$.

xv. Li, Wei, \& Moyer, M. (Ed.).(2008). The Blackwell guide to research methods in bilingualism and multilingualism.New York: Wiley

xvi. Meisel, J. M. (1989). Early differentiation of languages in bilingual children, in: K. Hyltenstam\& L. K. Obler (eds.) Bilingualism Across the Life Span. Aspects of Acquisition, Maturity and Loss. Cambridge: Cambridge University Press, 13-40.

xvii. Ouedraogo, R. M. (2000). Language planning and language policies in some selected West African countries. Burkina Faso: IICBA. 